\title{
O fenômeno dos "Estados emergentes" na política internacional contemporânea: contribuições da Economia Política Internacional para um objeto multi-aspectual
}

\author{
The phenomenon of the "Emergent Countries" \\ in the contemporary international politics: \\ contributions from International Political Economy \\ for a multi-aspectual object
}

DOI: $10.21530 /$ ci.v12n1.2017.615

Marina Scotelaro ${ }^{1}$

\section{Resumo}

A discussão do artigo se situa dentro do debate contemporâneo sobre a categorização de potências emergentes no capitalismo global, um fenômeno cada vez mais problematizado acerca da ascensão política e expressivo crescimento econômico dos Estados em desenvolvimento do Sul Global. A despeito da preexistência de um debate dentro de correntes tradicionais de relações internacionais, o resgate e a consolidação desses esforços analíticos no início do século XXI permitiram às teorizações econômicas uma crescente influência nos esforços interpretativos sobre tal aspecto do ambiente internacional. Entende-se que as abordagens interpretativas de relações internacionais que partem da economia política internacional fornecem atributos consistentes e são adequadamente correlacionados para compreender o posicionamento de países com crescente projeção internacional. Os avanços interpretativos possibilitaram novas compreensões sobre os fenômenos, mas a tentativa de dimensionar os Estados segundo sua potencialidade de influenciar na política internacional se torna problemática em função do seu nível de integração à economia capitalista global.

Palavras-chave: Estados Emergentes, Economia política internacional, Capitalismo, Governança Global.

1 Doutoranda em Relações Internacionais na PUC Minas; professora de Relações Internacionais no Centro Universitário de Belo Horizonte (UniBH). E-mail: marinascotelaro@gmail.com

Artigo submetido em 31/01/2017 e aprovado em 19/04/2017. 


\begin{abstract}
The discussion of this article is inserted into the contemporary debate about the categorization of Emerging powers in global capitalism, an increasingly problematized phenomenon regarding the political rise and significant economic growth of the developing States in the Global South. Despite the preexistence of a debate within traditional theories of International Relations, the recovery and the consolidation of these analytical efforts in the early twenty-first century allowed economic theorization a growing influence on interpretive efforts of this aspect of the international system. We believe that the interpretative approaches to International Relations derived from International Political Economy provide consistent attributes and are properly correlated to understand the positioning of countries with growing international projection. Interpretative advances made new understandings of the phenomena possible, but the attempt to scale the States by their capacity to influence international politics can become problematic depending on its level of integration into the global capitalist economy.
\end{abstract}

Keywords: Emergent States; Political Economy, Capitalism, Global governance.

\title{
Introdução
}

Um dos fenômenos da política internacional contemporânea com grande relevância nas relações internacionais é a crescente visibilidade alcançada por alguns Estados em desenvolvimento. A ascensão desses atores se dá em diversos níveis e setores, mas chama atenção a crescente participação dos mesmos nos fluxos econômicos internacionais, sobretudo no que tange ao seu crescimento econômico e sua capacidade de resposta à crise que atingiu o centro capitalista mundial no final da década de 2000.

As dificuldades de apreensão teórica desses fenômenos, de natureza diversa dos modelos de análise positivistas clássicos, são constantemente expostas. O "estadocentrismo" - manter o Estado como unidade de análise principal - e a "anarcofilia" - entender o sistema internacional como composto por unidades iguais - são tendências analíticas recorrentes que contaminam o entendimento de objetos inseridos em um contexto no qual o que prevalece empiricamente é a hierarquia entre os Estados (STEPHEN, 2014; ROBINSON, 2015). Tais descrições das relações internacionais se infiltraram na discussão de "potências médias" desde o começo das análises do fenômeno. Assim, essas transposições de elementos de teorias mainstream geraram implicações problemáticas e pouco adequadas às particularidades do objeto. 
A investigação teórica acerca das "potências emergentes" na academia de relações internacionais se estabeleceu a partir de diferentes abordagens no pós-guerra. O modelo funcional, a abordagem estrutural-sistêmica, a abordagem “intermediária” (de Robert Keohane) e o modelo behaviorista buscavam explicações acerca da forma como Estados industrializados não centrais se posicionavam no sistema e como o influenciavam. Tais abordagens se alternavam entre o foco na agência dos atores ou na determinação da distribuição de poder existente a partir da estrutura do sistema (HUELSZ, 2009, p. 30). O surgimento de cada interpretação está ligado a um contexto específico do campo e das relações internacionais. A cientificidade existente à época, seus aspectos disciplinares, modelavam as perspectivas analíticas mais recorrentes no momento para sua aplicação aos casos estudados.

Tais teorias, já em seu contexto, apresentaram deficiências para entender os Estados em emergência a partir da década de 1980. Uma crítica fundamental a tais abordagens é a ênfase artificial que as mesmas sustentam com relação à separação entre estrutura e agência. Outra crítica sustentava que a limitação de entender o poder somente em termos materiais ou ideacionais é insuficiente para compreender o papel das "novas” potências médias ou dos "novos" emergentes (HUELSZ, 2009, p. 27). Restringir sua relevância a assuntos secundários em relação ao núcleo duro da política internacional ou ampliá-la, a ponto de considerar tais nações como potenciais transformadoras da ordem, propositivas de um novo modelo de organização social, é tanto subestimar quanto superestimar suas características atuais. Os trabalhos subsequentes que trataram do conceito tentaram incorporar críticas dessa natureza, aproximando o conceito à realidade desses Estados não localizados no centro da comunidade ocidental.

É possível identificar alguns autores a partir da década de 1990 que incorporam em suas análises a diferenciação do contexto e dos atores em si para entender sua emergência fora do padrão de desenvolvimento industrializado. Contudo, algumas limitações persistiram, uma vez que os "novos emergentes" foram classificados segundo categorizações binárias tradicionais, pertencentes aos “desenvolvidos” ou “em desenvolvimento”, a depender do seu nível de desenvolvimento econômico (HUELSZ, 2009). A identificação desses padrões de enquadramento de casos em conceitos estabelecidos com outros propósitos teóricos gera inconsistências científicas, na medida em que traz ao conceito original elementos que poderiam ser mais bem acomodados em uma discussão qualitativamente diferenciada. 
Consideramos que os descaminhos do desenvolvimento teórico do conceito de "potências médias" - até as atuais perspectivas - ocorreram por conta da demasiada extensão de tal conceito, com objetivo de adequar diversos casos que compartilhariam alguns de seus atributos (HUELSZ, 2009). Há uma recorrente absorção nas relações internacionais dos conceitos baseados em objetos gerados por categorias referentes à realidade dos Estados do centro para analisar casos fora de seu contexto civilizacional específico. A limitação nesse tema tem um caráter (1) ontológico e (2) epistemológico. Em relação ao primeiro ponto, as unidades a que hoje nos referimos como "potências emergentes” (Brasil, China, Índia, África do Sul, Turquia, Arábia Saudita, dentre outros) possuem uma formação social interna diferenciada de uma economia capitalista e liberal, e que são transformadas por processos externos às suas fronteiras nacionais. Ademais, descolá-las de seu contexto de emergência específico, que delimita as possiblidades de ação dentro do modelo econômico vigente, nos impede de compreender seus limites de inserção e sua margem de contestação ou adesão ao sistema. Em segundo lugar, o debate sobre o papel e a influência internacionais desempenhados pelas "potências médias emergentes” é um típico problema teórico interdisciplinar e multinível muito caro à disciplina de relações internacionais.

A partir desse quadro, pontuamos alguns aspectos passíveis de problematização. A discussão não se contém em fronteiras teóricas bem definidas, uma vez que os padrões e indicadores para mensurar a influência de um Estado no sistema não são compartilhados nem mesmo por teóricos de uma mesma corrente interpretativa. Assumindo o contexto histórico atual como diverso daquele em que emergem as contribuições teóricas sobre as "potências médias", é imperativo compreendê-lo para identificar o potencial de emergência dos Estados na fase financeirizada do capitalismo. A própria configuração das unidades se diferencia frente ao contexto em que se começa as discussões sobre o tema. Logo, entender como as forças sociais internas de cada Estado respondem aos processos internacionais é também essencial.

O objetivo do trabalho é compreender, a partir das contribuições das abordagens baseadas na economia política internacional, os possíveis desdobramentos geopolíticos, econômicos e institucionais da ascensão das denominadas "potências emergentes" no sistema internacional contemporâneo. Esse trabalho avança na sistematização de alguns elementos teóricos que são capazes de apreender tendências empíricas para mapear os caminhos da caracterização de um Estado entendido como emergente no sistema. Só a partir de uma construção analítica assim é possível formar um quadro holístico do fenômeno. 
Algumas considerações terminológicas devem ser esclarecidas nesse momento para evitar entendimentos equivocados de termos recorrentes na literatura sobre o tema. Optamos por utilizar, como referência aos termos "potências médias", "potências emergentes", "potências médias emergentes", o termo Estados emergentes $^{2}$. Sobre a natureza do fenômeno, e apropriando-se da constatação para essa proposta de trabalho, "qualquer tentativa de se definir e especificar a identidade dos poderes emergentes poderia facilmente se tornar esotérica, idiossincrática particularmente inútil para o tema central sob análise nesse artigo"3 (THAKUR, 2014, p. 1791). Ainda, sobre o uso dos termos "Sul Global" e "Norte Global”: nos referimos não somente à divisão política comumente reconhecida entre economias avançadas e aquelas em outros níveis de desenvolvimento; optamos por considerar os conceitos de forma ampliada, que levam em conta as diversas hierarquizações geopolíticas de poder internacional ${ }^{4}$. Considera-se mais produtivo apresentar algumas possibilidades interpretativas sobre o fenômeno que de fato apontem para a amplitude de aspectos que o mesmo abarca. Ao tentarmos demonstrar suas limitações, não pretendemos restringir outras potenciais argumentações, mas nos posicionarmos no debate.

Prosseguiremos com a discussão a partir de três momentos. Dada a amplitude do fenômeno, apresentamos algumas problematizações acerca dos processos que envolvem a emergência dos Estados na contemporaneidade, o que demonstra como se configuram como objeto de análise para o entendimento do ambiente internacional. Na sequência, levantamos contribuições de autores da economia política internacional (EPI) que trabalham sobre os Estados emergentes e que dialogam com a configuração do sistema atual com os processos internos às unidades. A partir dessa discussão, elencamos alguns pontos sobre o quanto

2 Por "potência” entendemos o ator com um poder/papel potencial ainda não realizado de suas capacidades no sistema internacional - o que, utilizando o termo Estado, não implicaria comprometimento dessa análise. A classificação "média” situa o ator em um estrato da política internacional próximo à classificação da literatura tradicional, geralmente em arenas da chamada baixa política; por "emergente” classificamos aquele ator que passa a exercer um peso maior na política internacional em relação ao seu momento anterior em decorrência do incremento de seu poder em relação ao sistema como um todo.

3 Any attempt to define and specify the identity of "emerging powers" could quickly become esoteric, idiosyncratic and not particularly helpful for the central issue under analysis in this article.

4 A discussão sobre Sul Global e Norte Global, ainda que agrupe os Estados de acordo com posição geográfica que, em alguma medida, coincidira com seu nível de industrialização, deve ser vista de forma ampliada. Contemporaneamente, tal divisão ajuda a informar hierarquias sobrepostas entre várias dimensões da categoria de poder - de aspectos materiais a subjetivos. Ademais, vale ressaltar no momento da aplicação: 1) qual tipo de emergência é utilizado para classificação dos países; 2) levar em conta a heterogeneidade dos Estados localizados nos hemisférios Sul ou Norte, evitando uma classificação automática. 
podemos considerar os ditos Estados emergentes como reais ou potenciais transformadores da ordem internacional, tanto no que diz respeito aos aspectos materiais quanto aos ideacionais.

\section{Potencial analítico do fenômeno}

A dificuldade de teorização do fenômeno dos Estados emergentes decorre da multiaspectualidade dos elementos e dilemas recentes que os circundam. O processo de ascendência desses atores se inicia no último quartel do século XX, mas chama atenção sua discussão mais sistematizada e intensificada a partir do início do século XXI. Desde então, pululam publicações sobre as diversas dimensões do fenômeno, seja sobre o fortalecimento do Estado frente às crises econômicas, seja sobre a transnacionalização de suas economias; seu papel em organizações internacionais e outros fóruns multilaterais; e os dilemas sociais internos enfrentados por Estados que são "potências regionais"5. Nos últimos anos, edições especiais de periódicos acadêmicos da área de relações internacionais se dedicaram à forma como tais Estados emergentes do Sul Global se comportam frente ao consenso de Washington (BAN; BLYTH, 2013) e como se encaixam em um contexto de transformações da governança global (GRAY; MURPHY, 2013). $\mathrm{O}$ grau de distanciamento frente à ordem vigente vem sendo objeto caro às discussões sobre os Estados emergentes, sobretudo quando consideramos aqueles que buscam uma autonomia político-econômica no Sul Global.

A ideia de Sul Global como espaço político que concentra Estados que buscam sua autodeterminação data das pós-independências na segunda metade do século XX. Politicamente, a Conferência de Bandung, de 1955, e o movimento dos Estados não alinhados da década de 1960 forneceram elementos para um esforço intelectual que culminaria em proposições objetivas para uma ordem global posterior mais equânime. As ambições existentes no projeto da nova ordem econômica internacional da década de 1970 tinham o intuito de diminuir as disparidades econômicas internacionais entre os Estados centrais e os Estados periféricos, o que proporcionaria aos países em desenvolvimento a condução de seu próprio desenvolvimento socioeconômico (GOLUB, 2013). Os impasses enfrentados pelos Estados da periferia do capitalismo, em decorrência dos choques

5 O termo "potência regional" refere-se ao Estado que tem a capacidade de exercer influência sobre os outros atores que se localizam no seu espaço geográfico próximo. 
do petróleo nos anos de 1970, foram sentidos especialmente na América Latina e na Ásia com as crises da dívida e as crises monetárias das décadas de 1980 e 1990, respectivamente. O impacto econômico sofrido por esses países diluiu o esforço das décadas anteriores em construir uma força conjunta de governança global a partir de "baixo". Entretanto, a subsequente não transformação da ordem, a permanência da hegemonia estadunidense e da estrutura hierárquica do sistema não podem ser vistas como a falência do Sul Global. Tais momentos da história inauguram alguns dos aspectos observáveis nas reivindicações dos emergentes da contemporaneidade pela busca de uma maior equidade na governança global.

O século XXI se tornou palco de transformações político-econômicas globais que abriram canais para uma redefinição de papéis entre os Estados no ordenamento de tal forma que afetou a distribuição de poderes dentro do Sistema Internacional. O que difere a natureza dos demandantes atuais e os movimentos terceiro-mundistas das décadas anteriores é o intenso engajamento internacional, consequente da grande dimensão econômica que os primeiros alcançaram sem se distanciar da ordem hegemônica (GRAY; MURPHY, 2013). Os avanços de uma descentralização do poder na economia política internacional global não estão necessariamente relacionados a uma transformação dos princípios hegemônicos do sistema. A dizer, a participação de alguns Estados emergentes do Sul Global, que se distanciam cada vez mais da maioria dos outros países em desenvolvimento, não indica uma democratização do sistema no sentido de inclusão de todos os emergentes na governança global. A identificação do posicionamento dos Estados emergentes em várias arenas políticas e econômicas é essencial para desvelar se os países que mais vêm se destacando representam ou não os interesses daqueles pouco vocalizados internacionalmente.

Temas antes tratados como secundários para o dimensionamento do poder na agenda global são fundamentais para dimensionar o potencial dos Estados emergentes como transformadores da ordem. A reivindicação por parte de países como Brasil, China, Rússia e Arábia Saudita por uma ordem mais participativa, "mais justa”, não é reflexo das relações sociais que esses mantêm internamente. "Em resumo, muitos dos países mais desiguais do mundo demandam equidade nos fóruns globais" (CHANDHOKE, 2013, p. 311). Um dos aspectos passíveis de esvaziamento em tal contexto é o tratamento da questão da pobreza. Apropriado por organizações multilaterais de desenvolvimento, o reposicionamento do discurso sobre a erradicação da pobreza é tratado como tema de reforma e não de mudança

6 In sum, some of the most unequal countries in the world demand equality in global forums. 
estrutural na ordem (VAN DER WESTHUIZEN, 2012). A pobreza é um elemento característico dos países em desenvolvimento - o que inclui aqueles aqui tratados como emergentes. Para além de uma preocupação moral com o bem-estar social, o discurso da pobreza pode incorrer na armadilha de uma falsa canalização das demandas dos emergentes, uma vez que é um aspecto historicamente vinculado a instituições multilaterais. Qualificar quais são os temas e as reivindicações realmente genuínos e que aproximam os Estados emergentes de maior destaque no sistema internacional contemporâneo delimita as possibilidades analíticas de compreender as transformações em curso.

As tentativas de compreender o fenômeno estimularam agrupamentos de países a partir de alguns atributos supostamente compartilhados. Um relatório, com o objetivo de gerar novos destinos de investimento, publicado em 2001 (SACHS, 2001), provocou uma inflexão na forma de se entender os mercados de investimento, os ditos "mercados emergentes". O termo BRICs (Brasil, Rússia, Índia e China) desencadeou um processo em que o conhecimento produzido sobre o campo econômico gerou implicações políticas reais. Além de um aumento de transações econômicas, tais como investimentos diretos externos, politicamente isso também se evidencia, a partir do momento em que os países passaram a se reunir em cúpulas até a formalização de um banco de investimentos em 2015. Ainda que tal acrônimo não seja a razão de sua crescente influência internacional, a criação catalisou a emergência de "circuito cultural de capital" distinto (WANSLEBEN, 2013). A partir dos BRICs, uma série de agrupamentos reúne Estados sugerindo mercados e sociedades em "emergência".

Cada tentativa de sistematizar uma identidade diferente aos Estados agrupados gera novas potencialidades analíticas, mas pode incorrer no erro da extensão do conceito de “emergentes” a esferas impróprias. Agrupar Índia, Brasil e África do Sul (chamados IBSA) para uma estratégia mais proporcional entre as unidades parece coerente, até quando situamos os atores em seus respectivos contextos geopolíticos. Incorporar a China a esse grupo (transformando IBSA em BASIC), com o intuito de representar a periferia ascendente do capitalismo, levanta questões sobre a legitimidade de representação do grupo. Como será discutido adiante, o acrônimo BRICs (ou BRICS7 ) já agrega uma disparidade significativa entre seus membros.

\footnotetext{
7 A incorporação da África do Sul se dá em 2009, transformando o acrônimo em BRICS. A despeito disso, alguns trabalhos ainda mantém o grupo sem África do Sul por questões metodológicas referentes aos atributos utilizados para agrupá-los. Quando a referência não incorporar a África do Sul como integrante do grupo, manteremos o acrônimo como BRICs; e, quando incorporada, BRICS.
} 
Compreender os parâmetros e as categorizações são fundamentais para evitar o esvaziamento da discussão. As implicações políticas dessas tensões analíticas são importantes, uma vez que a transformação do conhecimento econômico pode alterar realidades materiais (WANSLEBEN, 2013).

Definir com clareza quais são os aspectos que indicariam um "Estado emergente" é uma das carências na literatura. Para os propósitos deste trabalho, consideramos que o termo

Emergência significa grupos de auto-organização que correspondem estrategicamente à economia política global na qual estão entrelaçados. Eles são organicamente adaptados à dinâmica do sistema. Os microelementos contribuem para a constituição de macrocomportamentos em um mundo crescentemente policêntrico. A política da emergência é parte crucial deste fenômeno. Vale enfatizar que a rubrica "mercados emergentes" omite a política e que a "poderes emergentes" ou "poderes em ascensão" negam a economia. Superar tal separação, com a implícita primazia tanto da economia quanto da política, parece adequado. ${ }^{8}$ (MITTELMAN, 2013, p. 26)

As interações entre o Estado, o mercado e a sociedade são fundamentais para compreender os limites e as possiblidades de atuação desses atores na governança global. Uma investigação acerca desse fenômeno envolve diferentes níveis de análise organicamente interligados sem uma separação entre fenômenos políticos e econômicos.

Os elementos ontológicos do fenômeno contemporâneo dos Estados emergentes perpassam "processos globalizantes, corporações transnacionais, regiões, Estados, organizações subnacionais e internacionais, cidades e estruturas sociais"9 (MITTELMAN, 2013). É nítida a dificuldade de compreender de forma coesa as diferentes possibilidades e modelos que serão introduzidos a partir desses processos que, ainda, se configuram como desordenados e espontâneos. Nisso, podemos incluir as continuidades e descontinuidades dos processos de integração regional e inter-regional; os caminhos alcançados por visões

8 Emergence denotes clusters of self-organisation that are responding strategically to the global political economy in which they are enmeshed. They are adapting organically to a dynamic system. The micro-elements contribute to constituting macro-behaviour in an increasingly polycentric world. The politics of emergence is a crucial part of this phenomenon. It is worth emphasizing that the rubric "emerging markets" omits the politics and that the header "emerging powers" or "rising powers" deflects the economics. Overcoming this separation, with its implicit primacy of either economics or politics, seems referable.

9 Globalising processes, transnational corporations, regions, states, international and subnational organizations, cities and social structures. 
emancipatórias dos emergentes; e o redimensionamento de forças políticas no plano internacional.

A transdisciplinaridade se impõe sobre o problema, sobretudo, ao considerarmos que suas bases se fundamentam e dependem de modificações no capitalismo global contemporâneo. Identificar os princípios do funcionamento do capitalismo, em sua fase financeira, e quais as possibilidades nos fluxos possíveis entre os Estados (seja no setor comercial, de investimento e/ou financeiro), é um ponto chave na discussão. Não é possível compreender o posicionamento das unidades do sistema sem o panorama geral sobre o qual as relações sociais e econômicas internacionais são estabelecidas. Apenas com uma abordagem capaz de vincular tais aspectos é possível avançar na compreensão das determinações.

\section{Contribuições da Economia Política Internacional}

Frente à necessidade de um diálogo mais coerente entre objeto/fenômeno e teoria, as abordagens críticas a partir da economia política internacional fornecem elementos interessantes. A validade de uma abordagem materialista histórica reside na capacidade de identificar a natureza da mudança do capitalismo, que incide diretamente sobre as relações nacionais entre Estado e sociedade. Em termos de avanço frente ao que já foi anteriormente proposto como opções teóricas, "usar um entendimento crítico de estrutura e agência ajuda a melhorar a forma de identificar e entender diferentes formas de poder"10 (HUELSZ, 2009, p. 64). Da mesma maneira, evita a separação instrumental entre questões econômicas e políticas, que são partes codeterminantes de um mesmo modo de produção social. A perspectiva da economia política internacional é capaz de incorporar elementos e processos que não se restringem aos limites territorialistas das abordagens mainstream.

As funções desempenhadas na dimensão transnacional das relações socioeconômicas transcendem o "estadocentrismo" clássico das teorias políticas e ressignificam a forma de inserção dos emergentes na economia global. A estrutura do capitalismo contemporâneo pode ser caracterizada como "híbrida": ao mesmo tempo em que se observa uma crescente integração transfronteiriça, acompanha-se uma erosão dos princípios liberais da governança global hegemônica

10 Using a critical understanding of structure and agency further helps to better identify and understand different forms of power. 
(STEPHEN, 2014). O Estado se diferencia historicamente a partir de seu modelo de regulação de mercado e o nível de transnacionalização de seus circuitos econômicos. Considerando-se que as alterações das forças sociais internas ocorrem em decorrência do processo de estruturação da econômica global (dado o nível de integração econômica), os interesses nacionais são moldados a partir do resultado dessas interações (STEPHEN, 2014; ROBINSON, 2010). O Estado, para os países emergentes, vive em função da dialética, que é organizar sua estrutura interna de forma que as elites domésticas possam se integrar transnacionalmente aos fluxos globais da economia.

Uma das especificidades dos Estados em desenvolvimento é a relação estabelecida por suas elites transnacionais em ascensão e as respectivas estruturas governamentais postas a seu serviço. O “capital transnacional” é a atual fração hegemônica do capitalismo constituída por elites ${ }^{11}$ internacionalizadas de diversas origens nacionais, interligadas por cadeias de valor produtivas ou financeiras (ROBINSON, 2010). Em países em desenvolvimento, tal processo ganha características diferenciadas.

A formação das classes transnacionais nos países em desenvolvimento é a maior dimensão da globalização capitalista. Na medida em que o capitalismo global penetra em novas esferas e as sujeitam com sua lógica de acumulação transnacional, as classes pré-globalizadas, tais como camponeses e artesãos, tendem a desaparecer, substituídos por novos grupos de classes subordinados e dominantes ligados à economia global. Geralmente, temos visto isso em países em desenvolvimento: a Ascenção de novos grupos dominantes e frações de classe ligadas à econômica global; a diminuição da mobilidade - ou proletarização - das antigas classes médias e estratos profissionais e a ascensão de novas classes trabalhadores rurais e urbanas ligadas aos processos de produção transnacional; a própria classe trabalhadora se tornou flexibilizada e informalizada; o aparecimento de uma massa expandida desde supranumerários ou marginalizados. ${ }^{12}$ (ROBINSON, 2010, p. 7)

11 Neste texto, partimos da definição de elite como uma parcela socioeconomicamente e politicamente dominante. Nos países em desenvolvimento, geralmente estão associados à administração do sistema político do Estado, ainda que não sejam capitalistas detentores dos meios de produção de valor. Não obstante, determinantes são suas funções ou colaborações para a reprodução do capital (ROBINSON, 2010, p. 3).

12 Transnational class formation in the developing countries is a major dimension of capitalist globalization. As global capitalism penetrates new spheres and subjects them to the logic of transnational accumulation, pre-globalization classes such as peasantries and artisans tend to disappear, replaced by new dominant and subordinate class groups linked to the global economy. We have generally seen in developing countries: the rise of new dominant groups and capitalist fractions tied to the global economy; the downward mobility - or proletarianization - of older middle classes and professional strata and the rise of new middle and professional 
A decorrente transformação na natureza clássica do Estado - espaço territorial onde se concentra o poder no monopólio da força - impõe desafios sobre problemas outrora reconhecidos como objetos do âmbito doméstico. Como projetar políticas para o desenvolvimento nacional quando os processos não são mais gerenciados no interior das fronteiras nacionais e são, ao mesmo tempo, dinamizados pelo nível de transnacionalização definida a partir da função exercida pelo Estado em sua inserção internacional?

Independente do grau de integração do Estado nas redes globais da economia mundializada, compreender o fenômeno de Estados emergentes exige compreender o comportamento das elites ou da classe capitalista transnacional. A plataforma política internacional de países, como, por exemplo, os membros do BRICS, é direcionada para uma associação mais profunda ao capitalismo por meio do capital transnacional. A integração na economia global vem sendo o caminho encontrado por países emergentes para incrementar seu poder econômico e sua influência política (ROBINSON, 2015) A clivagem Norte-Sul anterior é hoje melhor entendida em termos de uma divisão social transnacional em detrimento de uma divisão geopolítica. Talvez seja possível assinalar mais proximidades entre Estados do Norte e do Sul Global quando percebidos em uma perspectiva histórica mais ampla.

Por essa dificuldade em estabelecer os limites de uma "cooperação" entre esses Estados na concertação da ordem capitalista global, é essencial compreender os mecanismos que estabilizam a ordem e quais são os Estados que comportam as elites dirigentes determinantes para manter a ordem capitalista global. Assim, o questionamento do papel dos Estados Unidos como tutor da ordem acompanha os debates sobre a ascensão dos emergentes do Sul Global. Contudo, é relativizado o declínio dos Estados Unidos como centro de referência econômica mundial, sobretudo no que tange aos processos de estabilização monetária (STARRS, 2014). O grau de interdependência econômica hoje indicada pelo compartilhamento de ativos e títulos de dívidas, por exemplo, aparenta uma fuga analítica para ampliar a relevância dos BRIC, sobretudo quando sobressaltamos o montante que a China concentra da dívida pública estadunidense (VANAIK, 2013). As instituições de Bretton Woods de fato foram se colapsando ao longo dos anos, mas foram essenciais para a construção de uma hegemonia financeira sólida ainda desempenhada pelos Estados Unidos.

strata; proletarianization of peasants and artisans and the rise of new urban and rural working classes linked to transnational production processes; the working class itself become flexibilized and informalized; the appearance of an expanding mass of supernumeraries or marginalized. 
Essa hegemonia “autossustentável” não deve ser compreendida como um fenômeno pós-Guerra Fria. As condições estruturais existentes no momento do estouro da crise de 2008 são as mesmas da década de 1970. Há cerca de quase meio século, a desregulamentação do setor financeiro e o esvaziamento da estrutura intervencionista estatal aprofundou o caráter desigual do capitalismo (VANAIK, 2013). As crises econômicas são analiticamente ilustrativas para entender a dimensão da distribuição do poder no capitalismo atual. Momentos de turbulência prologada, como aqueles iniciados em 2008, são apenas episódios recorrentes em uma estrutura onde a instabilidade é o princípio ordenador. As particularidades de cada crise devem ser compreendidas a partir de cada momento histórico específico, quando a configuração do jogo de forças envolvidas redefine as caraterísticas geopolítico-econômicas. Na América Latina, durante a década de 1980, e na Ásia, na década de 1990, sobressaltaram-se as fragilidades da periferia com as crises da dívida para financiamento das contas públicas voltadas ao desenvolvimento industrial. De forma diversa, os finais da década de 2010 apontaram para a vulnerabilidade dos antes "credores" do sistema.

A fragilização das unidades centrais do sistema internacional abre espaço para os ganhos dos emergentes. Os débitos nas contas públicas são relativamente maiores nas economias ditas avançadas em relação aos Estados em desenvolvimento melhor estruturados macroeconomicamente. Contudo, o fato dos débitos estarem todos condicionados ao dólar estadunidense demonstra a capacidade de retroalimentação do sistema. Os choques externos ainda determinam com maior intensidade a vulnerabilidade daqueles Estados endividados pela moeda padrão internacional. Esse "privilégio" do hegêmona garante sua posição no sistema econômico internacional (ANTONIADES, 2013). A legitimidade da ordem dependerá da forma como se proporá a regulamentação dos fluxos financeiros e da dívida. Os Estados emergentes podem desempenhar um papel fundamental nessa nova configuração da governança global financeirizada.

E tal papel dependerá da forma como os Estados emergentes irão lidar com as contradições entre a penetração das finanças internacionais e o controle das relações sociais nacionais. Existem maneiras pelas quais os governos utilizam intencionalmente medidas monetárias ou financeiras para atingir seus propósitos de política externa. Compreender os propósitos dos ajustes econômicos realizados pelos Estados emergentes indica padrões de alinhamento ou não aos princípios regulatórios compartilhados internacionalmente (ARMIJO; KATADA, 2015; 
KATARIA, 2013) ${ }^{13}$. O uso intencional dessas estratégias tem como intuito principal reverter uma situação desfavorável ou mesmo transformar pressões financeiras em situações positivas para a economia. Dependendo do teor defensivo ou ofensivo da ampliação do crédito, da promoção de investimento ou da alavancagem de moedas, comportamentos unilaterais ou coordenados entre os Estados emergentes podem ser traduzidos em questionamentos na ordem. A continuidade de tais ações será traduzida em alterações na governança, o que inclui uma ressignificação dos princípios ordenadores que são legitimados por instituições multilaterais.

O papel das organizações internacionais é determinante na legitimação da natureza da governança global em andamento. Uma das características mais sistematizadas na literatura é sua função de representar os interesses do concerto de forças de um determinado momento histórico, servindo de instrumento dos Estados. Contudo, as contradições existentes no capitalismo global não são comportadas no interesse nacional dos Estados dominantes. As instituições internacionais são o locus onde são coordenadas essas contradições, conferindo-lhes uma relativa autonomia frente a tais interesses. Isso não significa que os princípios da ordem não coincidam com os Estados centrais, mas que algumas das demandas dos Estados emergentes são necessariamente incorporadas com o intuito de cooptar os contestadores da ordem. Não é sem propósito que a coordenação de ações entre o Banco Mundial e o Fundo Monetário Internacional incitam que

os países em desenvolvimento assumem a "direito" de políticas relevantes, “aceitando a responsabilidade pelo seu próprio desenvolvimento, e [adotando] estratégias vinculadas às circunstancias de seus países e envolvem uma ampla participação”, e os países industriais abrem seus mercados, elevam a ajuda e promovem o perdão da dívida [...] Isso prevê um comprometimento comum às “políticas certas” em promover a acumulação no nível doméstico, cooperar no nível global com o intuito de aumentar a estabilidade da economia mundial como um todo, e concertar esforços dentro e ente países individuais para assegurar a legitimidade de pacotes de políticas e iniciativas globais relacionadas. ${ }^{14}$ (CAMMARCK, 2003, p. 53)

13 Essa referência utiliza o financial statecraft como elemento para complementar a análise realista neoclássica aplicada para compreensão de como o uso intencional dessas medidas evitam uma perda de influência no sistema econômico (ARMIJO, KATADA, 2015).

14 The developing countries to assume "ownership" of the relevant policies, "accepting responsibility for their own development, and [adopting] strategies tailored to country circumstances and involving broad-based participation”, and upon the industrial countries to open their markets, increase aid, and provide debt relief [...] It envisaged a common commitment to "the right policies" to promote accumulation at domestic level, co-operation at global level in order to improve the stability of the world economy as a whole, and concerted efforts within and across individual countries to secure legitimacy for the policy packages and global initiatives concerned. 
Tal "adaptabilidade” da ordem é a maneira de controlar as contradições sistêmicas externalizadas nas disputas a partir do nível nacional. O quadro que se apresenta não contém elementos suficientes para configurar um declínio da fase neoliberal capitalista, mas somente possibilita o entendimento da forma como o sistema é organizado para absorver as crises cíclicas e os atores contestadores.

As evidências podem indicar uma transformação da ordem; entretanto, no sentido de transição de hegemonia, não há consistência sequer para demonstrar a superação da crise - entendendo-a como parte indissociável das transformações e adequações do funcionamento do sistema capitalista. Em termos teóricos, há um limite na compreensão do papel dos Estados emergentes quando agrupados. Entendê-los como um ator coletivo - mesmo que seus propósitos residam sobre a estabilização do sistema e o não questionamento da hegemonia - envolve um compartilhamento de interesses e valores que dificilmente se verifica nos casos apresentados. Esses limites se evidenciam ainda mais quando minuciados alguns indicadores específicos sobre setores econômicos entre os países do Norte e do Sul, e entre os próprios Estados emergentes.

\section{Limites e potencialidades de transformação da ordem}

A despeito de muitos avanços nas discussões acerca do fenômeno dos Estados emergentes, algumas questões permanecem em aberto. O nível de coesão pode ser definido a a partir dos limites de competitividade quando confrontados diretamente em setores econômicos determinantes para suas respectivas receitas. As relações entre os próprios emergentes são condicionadas às relações que possuem individualmente com os Estados centrais. Logo, as dificuldades de coordenação são complexificadas pelas posturas bilaterais já estabelecidas entre o Norte e o Sul Global. Existem elementos consistentes o suficiente para indicar que o declínio do modelo ocidental é inevitável e a transformação dos Estados emergentes, rumo ao patamar de "potência”, como inexorável?

De início, há evidências de uma diminuição do ritmo de crescimento dos indicadores econômicos dos Estados emergentes. Os setores econômicos mais relacionados e dependentes dos fluxos de capitais estrangeiros vêm sofrendo uma queda, em decorrência de um ciclo econômico positivo em torno dos preços das commodities. Seu recuo aconteceu com o advento da crise recente, demonstrando a contínua dependência sobre o setor primário exportador (STARRS, 2014). Ademais, 
a dominância dos Estados Unidos sobre alguns setores econômicos se manteve ou teve um acréscimo em termos relativos quanto a seu principal concorrente (STARRS, 2014). O crescimento verificado nos períodos anteriores à crise de 2008 não deve ser atribuído a um declínio dos Estados Unidos sem que esse seja devidamente qualificado. Sendo assim, as melhoras (que foram significativas) nos indicadores econômicos de países, como, por exemplo, os membros do BRIC, não alcançaram um patamar suficiente para desafiar a predominância estadunidense no direcionamento da agenda econômica.

Os padrões de crescimento elevado dos Estados emergentes corresponderam a um contexto favorável de estabilidade macroeconômica internacional e a um redirecionamento de atenção dos Estados centrais a suas realidades nacionais. Ademais, os BRICS enfrentam problemas internos de déficits estruturais, instabilidades políticas, insegurança social, dilemas sobre a capacidade de extensão interna do consumo (POORSAFAR, 2013). Entretanto, simbolicamente, suas implicações políticas têm repercussões importantes na redefiniçao dos parâmetros da governança global e isso será posteriormente retomado. Talvez sejam esses os elementos - com impactos degradantes para suas respectivas sociedades - que aproximam as unidades do acrônimo BRICS.

As ditas convergências em assuntos globais, que manteriam a unidades do grupo enquanto "emergentes", se baseia apenas em um nível genérico. Assuntos como mudanças climáticas, negociações sobre fluxos de comércio e aqueles ligados a algum tipo de intervenção militar por parte das potências centrais já são descompassados, dependendo do fórum em que se encontram. A China não só se distancia de outros países em desenvolvimento, como dos integrantes do G7715, em termos econômicos, como também destoa dos acrônimos dos quais faz parte. É em si o Estado impulsionador dos indicadores elevados nas demonstrações da crescente relevância dos emergentes. Sobre a China, podemos dizer que: (a) que tanto suas relações com a Rússia quanto com a Índia podem causar tensões internas à região asiática; (b) é um forte competidor frente ao potencial brasileiro de exportação; e (c) que levanta dúvidas "morais" sobre sua incursão desenfreada na África para escoar sua necessidade de crescimento econômico (PANT, 2013). Ou seja, a despeito do desejo de mudança do ordenamento econômico internacional que viabilizaria uma inserção mais vantajosa dos Estados

15 O G77 é um grupo de países em desenvolvimento institucionalizado dentro do âmbito da ONU, cujos objetivos centrais se resumem a uma coordenação de interesses econômicos e à promoção de uma cooperação entre Estados do Sul Global. 
emergentes, como deveria se configurar essa democratização sistêmica ainda é um assunto nebuloso.

Parte da dificuldade de consenso político mais claro entre os BRICs pode ser associada à forma como lidam com as convenções internacionais. A dificuldade em compreender até que ponto o Consenso de Washington é contestado pelos emergentes reside na adesão aos princípios macroeconômicos pré-determinados e às condicionalidades aceitas para obtenção de recursos internacionais. O Consenso de Washington não foi só um conjunto de proposições para estabilização da econômica; as recomendações disseminam uma cultura político-econômica neoliberal financista que condensa a natureza da hegemonia da fase contemporânea do capitalismo (BAN; BLYTH, 2013).

O Consenso de Washington não perdeu sua relevância como modelo estruturador macroeconômico, nem como paradigma político. O FMI, grande promulgador das ideias do Consenso, atingiu um grau de autonomia que lhe impõe a necessidade de aplicar as mesmas normas restritivas àqueles que outrora foram seus legitimadores, e que hoje sofrem com danos do sistema inflacionado - a situação europeia é representativa disso (FOURCADE, 2013). As estratégias dos BRICS não correspondem às prescrições mais liberais do Consenso de Washington; a intervenção estatal figura como o princípio contestador de Estados emergentes como o Brasil, a Rússia e a China. Entretanto, é equivocado considerar que o ordenamento internacional rumo à estabilidade macroeconômica como premissa para o desenvolvimento já não tenha sido introjetada à racionalidade dos Estados emergentes.

Os resultados econômicos positivos que carregam a alcunha de "emergentes" estão diretamente relacionados com medidas dessa natureza. Como consequência, viabilizaram o redirecionamento da atenção internacional para essas economias como novos destinos de investimento. Mas o que se tem é uma economia global definida em termos de desigualdade, construída historicamente a partir das diferenças de desenvolvimento tecnológico e dos ganhos resultantes da expansão comercial. Não existe tendência automática para uma "convergência” entre os Estados emergentes e as economias avançadas quando comparados os níveis de desenvolvimento dos mercados tecnológico, financeiro e comercial (SAAD-FILHO, 2014). O nível de crescimento econômico se deu de forma diferenciada entre os países em desenvolvimento. Os dois países com desempenhos destoantes foram a China e a Índia. Esse é um dos motivos pelo qual se elaboram proposições em que esses dois Estados emergentes seriam parte, ao lado de Estados Unidos, União 
Europeia e Rússia, de um "quinteto" hegemônico. Os problemas de interpretações como essas são observáveis quando se considera a incompatibilidade ideológicapolítica entre os atores, sobretudo no peso desproporcional que ainda reside nos Estados Unidos (VANAIK, 2013).

As formações entre Estados economicamente mais semelhantes podem ser mais prolíficas para interpretar os limites de ascensão dos Estados em desenvolvimento. Em razão da desproporcionalidade com a China - que dá mais peso ao BRICS ou ao BASIC - o IBAS foi iniciado em 2003 como contraposição às rodadas de negociações comerciais desfavoráveis ao Sul Global na Organização Mundial do Comércio. Essa é uma "atividade multilateral [que] pode de fato ter um potencial em deslegitimar a ordem mundial em curso. As variáveis são as condições globais objetivas e as concomitantes posições das elites"16 (TAYLOR, 2009, p. 47). As limitações de avanços institucionalizados emergem de várias frentes: das restrições impostas por suas instituições de cooperação regional, da sua incapacidade de se desvincular das regras econômicas internacionais e das suas tentativas estadocêntristas de lidar com processos globalizados. Ainda que haja a tendência de compreender essas coalizações em termos simbólicos, a ilusão acerca do real potencial transformador da ordem por parte de emergentes do Sul Global pode sobrevalorizar os aspectos proativos do fenômeno ao invés de elucidar seus aspectos reativos aos dilemas impostos pela necessidade de restruturação capitalista.

Em suma, "três [são os] aspectos do atual Sistema capitalista global: a contínua dominação dos EUA, a extraordinária ascensão do Resto (China em particular), e a estreita correlação entre tal ascensão e o índice de preços de matérias-primas"17 (STARRS, 2014, p. 95). O aspecto fundamental dessa caraterização é compreender que a elevação dos preços dos produtos de exportação dos países em desenvolvimento foi o motivo pelo qual a ascensão dos Estados em emergência se sustentou. Novas frentes econômicas foram abertas em decorrência da valorização financeira nesses mercados, mas seus limites esbarram em uma hegemonia estadunidense que se manteve em relação aos outros Estados no ambiente internacional. Pensar em uma concertação "contra-hegemônica” a partir de um "Consenso de Beijing” deve servir apenas como um conceito relacional para ressaltar os processos em curso, e não uma transição hegemônica inevitável (FOURCADE, 2013).

16 Multilateral activity (that) can in fact have a certain potential in de-legitimising the ongoing world order. The variable is objective global conditions and the concomitant positions of elites.

17 Three [are the] aspects of today's global capitalism system: the continued dominance of the US, the extraordinary rise of the Rest (China in particular), and the tight correlation between that rise and the raw materials price index. 
Os pontos levantados ao longo da discussão constituem parte da literatura referente ao tema proposto. Não foi nosso intuito esgotar as fontes e as perspectivas sobre o fenômeno dos Estados emergentes. Entendemos que apenas com o desenvolvimento futuro das relações entre tais atores será possível entender com clareza a dimensão da transformação sistêmica. A proposta chinesa de substituição da dependência internacional ao dólar estadunidense pode ter desdobramentos importantes na atual supremacia monetária internacional. As respostas a estes e a outros processos em curso devem ser compreendidos não apenas na realidade imediata, mas em relação aos seus determinantes anteriores e às prospecções que podem causar.

\section{Conclusões}

A compreensão do fenômeno dos Estados emergentes é uma das possiblidades interpretativas mais promissoras do campo de relações internacionais quando se pretende retratar o quadro político no sistema internacional do século XXI. Suas potencialidades analíticas provocam a necessidade de um diálogo interdisciplinar com outras ciências correlatas. Ao mesmo tempo, impele uma apreensão transdisciplinar entre os analistas internacionais que desejam enveredar por tais processos e entendimentos.

O que se chama hoje de “emergentes” difere substancialmente dos atores assim chamados nas abordagens realizadas no decorrer da segunda metade do século $\mathrm{XX}$, de onde se toma tal conceito. A discussão sobre a prevalência de afirmações terceiro-mundistas nas definições pode ser mais adequada do que as caracterizações tradicionais, que se restringiam a sociedades industriais já bem estabelecidas. Os avanços nas intepretações mais apropriadas à natureza desse fenômeno contemporâneo evitam alongamentos conceituais, cujos efeitos podem significar a perda de suas validades científicas.

As iniciativas de formação de acrônimos com o objetivo de apontar ações coordenadas entre os Estados emergentes - como os BRIC(S)s, IBSA, e BASIC facilitam a visualização dos blocos de poder que se contrapõem à ordem hegemônica neoliberal. Entretanto, cuidados mínimos são necessários quando comparamos atores com estruturas sociais internas tão díspares. A proximidade no posicionamento em relação a alguns temas globais não indica um compartilhamento irrestrito de concepções e valores. Um exemplo evidente é a diferença 
entre advogar em favor de uma "democratização do sistema internacional" e reivindicar o respeito à autodeterminação política interna, sobretudo, no que tange aos limites intervencionistas dos Estados em áreas hoje amplamente desregulamentadas e privatizadas.

As diferentes posturas dos Estados são também fruto dos seus processos individuais de crescimento e desenvolvimento. A forma como os Estados respondem aos desafios impostos pela transnacionalização financeira redefine as funções por eles despenhadas no sistema internacional e suas responsabilidades internas para a coesão social. Nesse ponto, a forma como suas elites dirigentes e suas elites integradas internacionalmente dialogam define suas probabilidades de aprimorar a própria inserção internacional.

A ordem capitalista contemporânea é marcadamente definida por processos de transnacionalização da produção de valor. Mais aguda ainda é a fluidez da formação de um capital fictício, responsável pela crescente instabilidade do sistema econômico internacional. As classes transnacionalizadas são cada vez mais "multinacionalizadas"; a cadeia de produção de valor nessa fase do capitalismo já se encrustou em diversas elites que se localizam não apenas nos países centrais, mas também nos Estados emergentes mais bem associados à dinâmica sistêmica. O nível de sensibilidade dos países é homogeneamente compartilhado, mas suas vulnerabilidades respondem a capacidades bem diferenciadas.

Questionar a existência de um hegêmona, uma ordem política unipolar dirigida por um Estado que teve perda de legitimidade política, não implica decadência inevitável do modelo capitalista que emergiu quando da ascensão de tal Estado. É fundamental atentarmos para qual o processo hoje em curso: a dificuldade de legitimação de uma hegemonia estatal talvez resida na crescente sustentação da ordem por elementos por ela autonomizados. Nesse aspecto, algumas instituições exercem papel essencial na legitimação dessa ordem fragilmente "autossustentada" - dada a recorrência de crises econômicas e de legitimação.

As organizações internacionais são capazes de agir em condescendência com os interesses dos Estados centrais, mas com forte interesse em adaptar suas estratégias político-econômicas à participação dos emergentes. A urgência da mudança de foco reside na lucidez de reconhecer que uma "nova governança global" exige uma redistribuição maior de custos e uma reconcentração de poder. A crescente atenção internacional frente às potencialidades dos mercados e dos Estados emergentes foi em si parte de um processo de ressignificação do entendimento econômico e das novas necessidades do capital internacional. 
O início deste milênio inaugura uma nova fase de ideias que foram introjetadas e posteriormente alcançaram as realidades econômicas dos Estados envolvidos.

A história recente da América Latina fornece um exemplo claro de como as ideias, no plano econômico, têm potencial transformador da realidade internacional. No período pós-II Guerra, o discurso internacional era voltado para industrialização e expansão do mercado interno. A Comissão Econômica para América Latina foi um órgão preponderante na disseminação dessas diretrizes. De caráter policy-oriented sob os auspícios da Organização das Nações Unidas, sempre teve seu respaldo. Com a crise da dívida e as medidas de austeridade impostas pelos pontos do Consenso de Washington, não apenas as práticas discursivas se voltaram para uma integração dos mercados internacionalmente, como foi assumida a orientação de políticas macroeconômicas pré-determinadas para atingir tal fim. Ligeiramente oposto ao período anterior, esse foi um dos meios de vocalização do discurso neoliberal (ROBINSON, 2010).

Os acrônimos formados nos últimos anos têm um alto potencial contestador, quando comparados ao que havia de potencial no grupo de países latino-americanos endividados que poderiam ter imposto a moratória coordenadamente em 1980. Como ressaltamos durante o artigo, identificar as especificidades históricas nesses processos é fator chave no entendimento do que pode vir a ser essa "nova governança global”. As qualificações são necessárias quando comparamos em termos absolutos e relativos o crescimento econômico real dos Estados emergentes em relação aos Estados centrais.

\section{Referências}

ANTONIADES, Andreas. Recasting the Power Politics of Debt: structural power, hegemonic stabilisers and change. Third World Quarterly, v. 34, n.2, 2013, p. 214-232.

ARMIJO, Leslie Elliott; KATADA, Saori N. Theorizing the Financial Statecraft of Emerging Powers. New Political Economy, v. 20, n. 1, 2015, p. 42-62.

BAN, Cornel; BLYTH, Mark. The BRICs and the Washington Consensus: An introduction. Review of International Political Economy, v. 20, n. 2, 2013, p. 241-255.

CAMMACK, Paul. The Governance of Global Capitalism: A New Materialist Perspective. Historical Materialism, vol. 11, n.2, 2003, p. 37-59.

CHANDHOKE, Neera. Realising Justice. Third World Quarterly, v. 34, n. 2, 2013, p. 305-320. FOURCADE, Marion. The material and symbolic construction of the BRICs: Reflections inspired by the RIPE Special Issue. Review of International Political Economy, v. 20, n. 2, 2013, p. 256-267. 
GOLUB, Philip S. From the New International Economic Order to the G20: how the 'global South' is restructuring world capitalism from within. Third World Quarterly, v. 34, n.6, 2013, p. 1000-1015.

GRAY, Kevin; MURPHY, Craig N. Introduction: rising powers and the future of global governance. Third World Quarterly, v. 34, n. 2, 2013, p. 183-193.

HUELSZ, Cornelia. Middle Power Theories and Emerging Powers in International Political Economy: A Case Study of Brazil. University of Manchester (PhD): Faculty of Humanities, School of Social Sciences, 2009.

KATARIA, Anuradha. Future of BRICS - the world is not flat! International Affairs Forum, v. 4, n. 2, 2013, pp. 142-144.

MITTELMAN, James H. Global Bricolage: emerging market powers and polycentric governance. Third World Quarterly, v. 34, p. 1, 2013, p. 23-37.

PANT, Harsh V. The BRICS Fallacy. The Washington Quarterly, v. 36, n. 3, 2013, p. 91-105. POORSAFAR, Hamid. BRICing down? A new normal for the BRICs. International Affairs Forum, v. 4, n. 1, 2013, p. 59-61.

ROBINSON, William I. Global Capitalism Theory and the Emergence of Transnational Elites. Working Paper No 02. UNU-WIDER. 2010.

ROBINSON, William I. he transnational state and the BRICS: a global capitalism perspective. Third World Quarterly, v. 36, n.1, 2015, p. 1-21.

SAAD-FILHO, Alfredo. The 'Rise of the South': Global Convergence at Last? New Political Economy, v. 19, n. 4, 2014, p. 578-600.

SACHS, Goldman. Building Better Global Economic BRICs. Global Economics Paper No. 66, 2001.

STARRS, Sean. The Chimera of Global Convergence. New Left Review, n. 87, 2014, p.81-96. STEPHEN, Matthew D. Rising powers, global capitalism and liberal global governance: A historical materialist account of the BRICs challenge. European Journal of International Relations. 2014, p.1-27.

TAYLOR, Yan. 'The South Will Rise Again'? New Alliances and Global Governance: The India-Brazil-South Africa Dialogue Forum. Politikon, v. 36, n.1, 2009, p. 45-58. THAKUR, Ramesh. How representative are brics? Third World Quarterly, v. 35, n. 10, 2014, p. 1791-1808.

VAN DER WESTHUIZEN, Janis. Falling on Fertile Ground? The Story of Emerging Powers' Claims for Redistribution and the Global Poverty Debate. Global Society, v. 26, n. 3, 2012, p. 331-350.

VANAIK, Achin. Capitalist Globalisation and the Problem of Stability: enter the new quintet and other emerging powers. Third World Quarterly, v. 34, n,2, 2013, p. 194-213. WANSLEBEN, Leon. Dreaming with BRICs. Journal of Cultural Economy, v. 6, n. 4, 2013, p. $453-471$. 